\title{
Male Pronuclear Formation and Blastocyst Formation Are Improved by Supplementation of Ascorbic Acid 2-O- $\alpha$ - Glucoside During In Vitro Maturation Culture of Denuded Porcine Oocytes
}

\author{
Hideki TATEMOTO'), Takuro OKUDA ${ }^{1)}$, Noriko SOGO'1) and Norio MUTO ${ }^{1)}$ \\ 1) School of Bioresources, Hiroshima Prefectural University, Shobara, Hiroshima 727-0023, \\ Japan
}

\begin{abstract}
The present study was conducted to examine the effect of ascorbic acid (AsA) on the cytoplasmic maturation of cumulus-denuded porcine oocytes during in vitro maturation (IVM) culture. After mechanical removal of cumulus cells, cumulus-denuded oocytes (DOs) were cultured for $44 \mathrm{~h}$ in BSA-free NCSU37 supplemented with cysteine, gonadotropins, 10\% porcine follicular fluid, and 0 to $750 \mu \mathrm{M}$ ascorbic acid 2-O- $\alpha$-glucoside (AA-2G), a stable ascorbate derivative, and then assessed for their developmental changes, including the progression of meiosis, in vitro fertilization (IVF) parameters and subsequent embryo development. Treatment with $250 \mu \mathrm{M}$ AA-2G during IVM culture in DOs showed no influence on the rates of maturation (60-61\%), sperm penetration (86\%), and polyspermy $(69-71 \%)$ following IVF, but enhanced the ability (43\%) to form male pronucleus (MPN) compared to that of DOs treated without AA-2G $(20 \%)(P<0.05)$. Although this rate of MPN formation of DOs was still lower than that of COCs $(66 \%)(P<0.05)$, the addition of $250 \mu \mathrm{M} \mathrm{AA}-2 \mathrm{G}$ to maturation medium in DOs apparently enabled IVM-IVF-derived zygotes to develop to the blastocyst stage $(3 \%)$. The levels of intracellular AsA and glutathione in DOs matured with AA-2G were significantly higher than those in DOs matured without AA-2G $(P<0.05)$. Moreover, the length of DNA migration, analyzed using the comet assay, was increased by oxidative damage in DOs treated without AA-2G during IVM culture, but treatment with AA-2G abated DNA damage, indicating that intracellular AsA supplied by AA-2G can potentiate the cellular protection of oocytes against oxidative stress through its scavenging activity during IVM culture. Thus, the present findings suggest that the preventing oxidative stress in oocytes during meiotic maturation supports the cytoplasmic maturation responsible for the subsequent developmental competence post-fertilization. Key words: Cumulus-denuded porcine oocytes, Ascorbic acid 2-O- $\alpha$-glucoside, Cytoplasmic maturation, Oxidative stress, Male pronuclear formation
\end{abstract}

(J. Reprod. Dev. 47: 329-339, 2001)

$\mathbf{T}$ he mammalian oocyte and its surrounding cumulus cells are metabolically coupled through gap junctions, that provide a unique means of entry into the ooplasm for several metabolites [1,2]. Cumulus cells have a close connection with oocytes during the process of

Accepted for publication: August 25, 2001

Correspondence: H. Tatemoto maturation in mammals [3, 4]. It is generally accepted that cumulus cells support the maturation of oocytes to the metaphase II (M-II) stage and enhance the cytoplasmic maturation responsible for the subsequent developmental competence post-fertilization. Several studies have indicated that cumulus-denuded oocytes (DOs) can undergo 
meiotic maturation in mice [5], rats [6], sheep [7] and cattle $[8,9]$ in vitro. The presence of cumulus cells during maturation culture was dispensable for sustaining the nuclear maturation of bovine oocytes, although the developmental competence of DOs after in vitro fertilization (IVF) was markedly lower than that of cumulus-oocyte complexes (COCs), indicating that the poor developmental competence of DOs might be caused by the lack of cytoplasmic maturation with progression to meiotic division $[8,10]$. Recently, Geshi et al. [11] reported that two normal calves could be derived from DOs matured in serum-free medium with $0.2 \mathrm{mM}$ sodium pyruvate. It seems that the addition of sodium pyruvate to IVM medium partly improves the developmental competence of bovine DOs. However, the functional role of cumulus cells in supporting cytoplasmic maturation is still unknown.

In our previous study [12], cumulus cells coupled to porcine oocytes efficiently prevented COCs against cell damage caused by oxidative stress during in vitro maturation (IVM) culture through the elevation of intracellular glutathione (GSH) content in the oocytes. In contrast, GSH content in DOs markedly decreased, and exposure of DOs to reactive oxygen species resulted in increasing the frequency of apoptotic cell death with DNA damage, as judged by an increase in the length of DNA migration. GSH is a major nonproteinous sulfhydryl compound in mammalian cells, and is well known to play an important role in protecting the cell from oxidative damage [13]. It is, therefore, speculated that the mediations of antioxidants, as a substitute for cumulus cells, may be partly associated with enhancement of cytoplasmic maturation in the oocytes.

In general, L-ascorbic acid (AsA) has functions in many biological processes such as the biosynthesis of collagen and other components of the extracellular matrix, and has been considered to be the most important antioxidant in extracellular fluids [14, 15]. A large amount of AsA was contained in preovulatory follicles in rat ovaries [16], and AsA exerted the prevention of follicular apoptosis in cultured rat [17] and mouse [18] follicles. However, AsA is unstable under various oxidative conditions such as exposure to neutral $\mathrm{pH}$, heat, light and heavy metals, resulting in rapid degradation $[19,20]$. In contrast to AsA, a newlysynthesized AsA derivative, ascorbic acid 2-O- $\alpha$ - glucoside (AA-2G), is characterized by its high stability toward thermal and oxidative degradation in neutral solutions and its non-reducibility [20,21]. Therefore, the present study was conducted to examine whether the addition of AA-2G to maturation medium supported the cytoplasmic maturation responsible for the subsequent developmental competence by protecting porcine DOs against oxidative damage. Meiotic maturation, IVF parameters, subsequent embryo development, AsA and GSH contents, and DNA damage were investigated in DOs matured in medium supplemented with or without AA-2G and compared with the values from COCs matured without AA-2G.

\section{Materials and Methods}

All chemicals used in the present study were purchased from Sigma Chemical Company (St. Louis, MO, USA) unless otherwise stated.

\section{Collection of oocytes}

Ovaries were collected from maturing gilts at a local slaughterhouse and transported to the laboratory in $0.9 \%$ (w:v) $\mathrm{NaCl}$ containing $100 \mathrm{mg} / 1$ kanamycin sulfate (Meiji Seika, Tokyo, Japan) at $30 \mathrm{C}$. Within $2 \mathrm{~h}$ post-slaughter, the follicular contents were recovered by excising the visible small antral follicles (about 2-6 mm in diameter) on the ovarian surface with a razor, and by scraping the inner surface of the follicle walls with a disposable surgical blade. Only COCs with a uniform ooplasm and a compact cumulus cell mass were collected. They were washed three times with Tyrode's Lactate (TL)-Hepes medium containing $0.01 \%(\mathrm{w}: \mathrm{v})$ polyvinyl alcohol (TL-Hepes-PVA). Some oocytes were freed from cumulus cells by repeated passage through a narrow-bore pipette to obtain DOs.

\section{Maturation culture of oocytes}

The basic medium used for oocyte maturation was BSA-free NCSU37 (NCSU37; [22]) supplemented with $0.6 \mathrm{mM}$ cysteine, 0.04 units $/ \mathrm{ml}$ ovine FSH, 0.02 units/ml ovine LH, 10\% (v:v) porcine follicular fluid, and 0 to $750 \mu \mathrm{M}$ AA-2G (Hayashibara Biochem. Lab., Okayama, Japan), or $250 \mu \mathrm{M}$ AsA. Porcine follicular fluid was aspirated from follicles of 2 to $6 \mathrm{~mm}$ in diameter, centrifuged 
at $10,000 \times g$ for $15 \mathrm{~min}(4 \mathrm{C})$, filtered through membrane filters with $1.0-\mu \mathrm{m}$ pores, and stored at $-30 \mathrm{C}$ until use. After washing in basic medium, groups of 20 DOs or COCs were transferred into $100-\mu$ l droplets of the basic medium, which had been previously equilibrated in a $\mathrm{CO}_{2}$ incubator. After $20 \mathrm{~h}$ of maturation culture, the oocytes were washed and transferred to $100-\mu$ l droplets of the basic medium without hormonal supplementation for an additional $24 \mathrm{~h}$ of culture. All media containing DOs and COCs were covered with mineral oil and cultured at $39 \mathrm{C}$ in an atmosphere of $5 \% \mathrm{CO}_{2}$ in air.

\section{IVF}

After total maturation culture of $44 \mathrm{~h}$, COCs were sucked through a narrow-bore pipette to remove their cumulus cells in TL-Hepes-PVA containing $0.1 \%(\mathrm{w}: \mathrm{v})$ hyaluronidase. The oocytes were washed three times with modified Tris-buffered medium (mTBM; [23]), designated as IVF medium supplemented with $2 \mathrm{mM}$ caffeine sodium benzoate and $0.1 \%(\mathrm{w}: \mathrm{v})$ BSA. After washing, 2530 oocytes were transferred to $50-\mu$ l droplets of IVF medium that had been covered with warm mineral oil. The droplets containing oocytes were kept in the incubator for 30 to 45 min until spermatozoa were added for fertilization. For sperm preparation, frozen-ejaculated boar spermatozoa were thawed (39 C) and washed two times by centrifugation at $400 \times g$ for 4 min in Dulbecco's PBS (Gibco BRL, Grand Island, NY, USA) supplemented with $0.1 \%$ (w:v) PVA at pH 7.2. At the end of the washing procedure, the sperm pellet was resuspended at $4 \times 10^{8}$ cells $/ \mathrm{ml}$ in $\mathrm{mTBM}$ supplemented with $4 \mathrm{mM}$ caffeine sodium benzoate and $0.4 \%(\mathrm{w}: \mathrm{v})$ BSA; they were then incubated for $90 \mathrm{~min}$ at $39 \mathrm{C}$. After sperm preincubation, $50 \mu$ lof diluted sperm suspension in IVF medium were added to a droplet containing oocytes for a final sperm concentration of $1 \times 10^{6}$ cells $/ \mathrm{ml}$. Oocytes were coincubated with spermatozoa for $7 \mathrm{~h}$ at $39 \mathrm{C}$ in an atmosphere of $5 \%$ $\mathrm{CO}_{2}$ in air.

\section{Embryo culture}

After insemination, oocytes were removed from fertilization drops, washed three times in NCSU37 medium, transferred (20-25 embryos) to $50 \mu$ of the same medium, and cultured at $39 \mathrm{C}$ in an atmosphere of $5 \% \mathrm{CO}_{2}$ in air until $168 \mathrm{~h}$ after IVF without any medium changes. At 48 and $168 \mathrm{~h}$ after IVF, the cleavage rate and blastocyst formation, respectively, were evaluated under a stereomicroscope.

\section{Assessment of meiotic maturation and fertilization parameters}

After IVM culture or $10 \mathrm{~h}$ after IVF, groups of 3040 oocytes were mounted, fixed in acetic acidethanol $(1: 3, v: v)$ for $72 \mathrm{~h}$, stained with $1 \%(\mathrm{w}: \mathrm{v})$ lacmoid in $45 \%$ (v:v) acetic acid, and examined for nuclear maturation or fertilization parameters, respectively, under a phase-contrast microscope at $\times 400$ magnification. Germinal vesicle breakdown (GVBD), maturation to the M-II stage, sperm penetration, polyspermy and MPN formation were assessed. Oocytes were considered to have been penetrated by spermatozoa at the M-II stage when they had two polar bodies, one or more swollen sperm head(s), and/or MPN and their corresponding sperm tail.

\section{Determination of AsA}

Intracellular AsA levels of the oocytes were determined by high-performance liquid chromatography (HPLC) analysis as described previously [24] with the following modifications. Porcine DOs and COCs cultured in medium with or without $250 \mu \mathrm{M}$ AA-2G as well as oocytes freshly isolated from their follicles (freshly isolated oocytes) were vortexed in TL-Hepes-PVA containing $0.1 \%(\mathrm{w}: \mathrm{v})$ hyaluronidase at the maximum speed for $1 \mathrm{~min}$ to remove cumulus cells completely, and then washed three times in coldPBS supplemented with $0.01 \%(w: v)$ PVA. Immediately, groups of 100 oocytes were put into microtubes containing $10 \mu 1$ of $1.5 \%$ (w:v) metaphosphoric acid solution ( $\mathrm{pH} 3.5)$. The samples were centrifuged for $10 \mathrm{~min}$ at $12,000 \times \mathrm{g}$ $(4 \mathrm{C})$, and the supernatants were analyzed on a Shim-pack ODS column $(6 \times 150 \mathrm{~mm}$; Shimadzu, Kyoto, Japan). The oocytes were extracted and chromatographed by HPLC on the same day. The HPLC system was equipped with a pulsation damper set between the pump and injector, and a UV-VIS detector Model SPD-10A (Shimadzu). The mobile phase was $0.1 \mathrm{M} \mathrm{KH}_{2} \mathrm{PO}_{4}-\mathrm{H}_{3} \mathrm{PO}_{4}$ buffer $(\mathrm{pH}$ 2.0) containing $10 \mu \mathrm{g} / \mathrm{ml}$ EDTA with a flow rate of $0.7 \mathrm{ml} / \mathrm{min}$. The absorbance of AsA was monitored at $240 \mathrm{~nm}$. The standard AsA solution was freshly prepared at a concentration of $1 \mathrm{mM}$ in $1.5 \%(\mathrm{w}: \mathrm{v})$ 
metaphosphoric acid solution and diluted immediately before use.

\section{Assay of GSH content}

Oocytes treated with or without $250 \mu \mathrm{M} \mathrm{AA-2G}$, in addition to freshly isolated oocytes, were assayed for GSH content. All oocytes were washed three times in the stock buffer $(0.2 \mathrm{M}$ sodium phosphate buffer containing 10 mM EDTA, pH 7.2), and groups of 40 oocytes in $5 \mu \mathrm{l}$ of stock buffer were transferred to $1.5 \mathrm{ml}$ microtubes, and $5 \mu \mathrm{l}$ of $1.25 \mathrm{M}$ $\mathrm{H}_{3} \mathrm{PO}_{4}$ was added. Samples were stored at $-80 \mathrm{C}$ until assay. The concentration of intracellular GSH in oocytes was determined using the 5,5-dithiobis(2-nitro-benzoic acid)-glutathione disulfide (DTNB-GSSG) reductase recycling assay as described previously [12], which detects both GSH and GSSG in the oocyte.

\section{Analysis of DNA damage}

Oocytes treated with or without $250 \mu \mathrm{M} \mathrm{AA-2G}$, in addition to freshly isolated oocytes, were transferred into $0.1 \%(\mathrm{w}: \mathrm{v})$ protease solution in TLHepes-PVA at room temperature to remove the zona pellucida, and were then washed quickly in PBS containing $0.3 \%(\mathrm{w}: \mathrm{v})$ BSA. DNA damage as an indicator of oxidative stress was detected by a single cell microgel electrophoresis (comet) assay reported by Singh et al. [25] and Tatemoto et al. [12] with the following modifications. Fifteen to twenty zona-free oocytes were mixed with $10-\mu$ l drops of 2\% (w:v) low-melting agarose (SeaPlaque GTG agarose; FMC BioProducts, Rockland, ME, USA) at $40 \mathrm{C}$ on the glass slide, and the cell suspension was immediately covered with a coverslip. The space between the coverslip and the glass slide was filled with $2 \%$ low-melting agarose, and the slides were then kept at $4 \mathrm{C}$ for $10 \mathrm{~min}$ to allow solidification of the agarose. After gently removing the coverslip, the slides stuck with the oocytes-embedded agarose were immersed in a lysing solution $(1 \% \mathrm{~N}$ lauroyl-sarcosine, $2.5 \mathrm{M} \mathrm{NaCl}, 20 \mathrm{mM}$ EDTA, 10 $\mathrm{mM}$ Tris, $\mathrm{pH} 10$, and $1 \%$ Triton $\mathrm{X}-100$ ) for $1 \mathrm{~h}$ to lyse the cells and permit DNA unfolding. The slides were then placed on a horizontal gel electrophoresis unit and equilibrated for $20 \mathrm{~min}$ in TBE electrophoresis buffer. Electrophoresis was conducted for $20 \mathrm{~min}$ at $50 \mathrm{~V}$. After electrophoresis, the slides were stained with $10 \mu \mathrm{g} / \mathrm{ml}$ bisbenzimide Hoechst 33342 for $10 \mathrm{~min}$, washed with distilled water, and then covered with a coverslip. The slides were sealed with clear nail polish and examined using a fluorescence microscope. The length of the streak of the DNA comet tail between the edge of the plasma membrane and the end of the visible comet tail was individually measured in 30-40 oocytes of each experimental group using a micrometer.

\section{Statistical analysis}

Statistical analyses of findings from four replicate trials for each treatment comparison were carried out by ANOVA and Fisher's protected least significant difference test using the STATVIEW program (Abacus Concepts, Inc., Berkeley, CA, U.S.A.). All percentage values were subjected to arcsine transformation before statistical analysis. Values are expressed as the mean \pm SEM. A probability of $P<0.05$ was considered to be statistically significant.

\section{Results}

Effects of treatment with AA-2G during IVM of DOs on nuclear maturation, fertilization parameters, and embryo development

When porcine DOs were cultured for $44 \mathrm{~h}$ in the absence or presence of increasing AA-2G concentrations, ranging from 100 to $750 \mu \mathrm{M}$, the treatment with AA-2G at a concentration of $500 \mu \mathrm{M}$ or greater caused a decrease in the incidences of GVBD and oocyte maturation up to the M-II stage (Table 1), but there was no difference in the meiotic progression among DOs treated with 0,100 , and $250 \mu \mathrm{M}$ AA-2G and $250 \mu \mathrm{M}$ AsA. These proportions of GVBD and maturation in DOs were significantly lower than those in COCs. Although no difference was found in the proportions of penetration $(77-86 \%)$, polyspermic fertilization $(61-71 \%)$ and mean number of spermatozoa per oocyte (2.1-2.4) despite the treatment with various concentrations of AA-2G during IVM culture (Table 2), the MPN formation rates of DOs matured with AA-2G were dose-dependently increased with the maximum value $(43 \%)$ at $250 \mu \mathrm{M}$, which was significantly higher than that of DOs matured without AA-2G $(20 \%)$ or with $250 \mu \mathrm{M}$ AsA $(28 \%)$ $(P<0.05)$. However, this value was considerably lower than that in COCs (66\%). These findings suggest that $250 \mu \mathrm{M}$ of AA-2G added to maturation medium is the optimum for supporting 
Table 1. Effect of AA-2G or AsA treatment during IVM on meiotic division of porcine oocytes

\begin{tabular}{|c|c|c|c|c|}
\hline \multirow{2}{*}{$\begin{array}{l}\text { Type of } \\
\text { oocytes }\end{array}$} & \multirow{2}{*}{$\begin{array}{l}\text { Treatment } \\
\text { during IVM }\end{array}$} & \multirow{2}{*}{$\begin{array}{c}\text { No. of oocytes } \\
\text { examined }\end{array}$} & \multicolumn{2}{|c|}{ Number of oocytes } \\
\hline & & & GVBD (\%) & M-II (\%) \\
\hline \multirow{2}{*}{ DOs } & $0 \mu \mathrm{m}$ & \multirow{2}{*}{125} & 93 & 76 \\
\hline & AA-2G & & $(74.6 \pm 3.6)^{\mathrm{a}}$ & $(61.2 \pm 6.2)^{\mathrm{a}}$ \\
\hline \multirow{2}{*}{ DOs } & $100 \mu \mathrm{m}$ & \multirow{2}{*}{126} & 91 & 75 \\
\hline & AA-2G & & $(72.4 \pm 1.7)^{\mathrm{a}}$ & $(59.7 \pm 2.7)^{\mathrm{a}}$ \\
\hline \multirow{2}{*}{ DOs } & $250 \mu \mathrm{m}$ & \multirow{2}{*}{130} & 100 & 78 \\
\hline & AA-2G & & $(76.8 \pm 2.1)^{\mathrm{a}}$ & $(59.8 \pm 4.9)^{\mathrm{a}}$ \\
\hline \multirow{2}{*}{ DOs } & $500 \mu \mathrm{m}$ & \multirow{2}{*}{126} & 89 & 64 \\
\hline & AA-2G & & $(71.1 \pm 3.0)^{\mathrm{a}}$ & $(51.1 \pm 3.7)^{\mathrm{a}}$ \\
\hline \multirow{2}{*}{ DOs } & $750 \mu \mathrm{m}$ & \multirow{2}{*}{133} & 75 & 47 \\
\hline & AA-2G & & $(56.6 \pm 4.5)^{\mathrm{b}}$ & $(35.9 \pm 5.7)^{\mathrm{b}}$ \\
\hline \multirow{2}{*}{ DOs } & $250 \mu \mathrm{m}$ & \multirow{2}{*}{127} & 89 & 72 \\
\hline & AsA & & $(69.9 \pm 2.6)^{\mathrm{a}}$ & $(56.7 \pm 2.8)^{\mathrm{a}}$ \\
\hline \multirow{2}{*}{ COCs } & $0 \mu \mathrm{m}$ & \multirow{2}{*}{115} & 100 & 96 \\
\hline & AA-2G & & $(87.1 \pm 1.1)^{c}$ & $(83.4 \pm 0.7)^{c}$ \\
\hline
\end{tabular}

$\mathrm{GVBD}=$ germinal vesicle breakdown; $\mathrm{M}-\mathrm{II}=$ metaphase II.

${ }^{a-c}$ Values with different superscripts in the same column are significantly different $(P<0.05)$.

Table 2. Effect of AA-2G or AsA treatment during IVM on fertilization parameters of porcine oocytes

\begin{tabular}{|c|c|c|c|c|c|c|c|}
\hline \multirow[b]{2}{*}{$\begin{array}{l}\text { Type of } \\
\text { oocytes }\end{array}$} & \multirow{2}{*}{$\begin{array}{c}\text { Treatment } \\
\text { during IVM }\end{array}$} & \multirow[b]{2}{*}{$\begin{array}{c}\text { No. of } \\
\text { oocytes } \\
\text { examined }\end{array}$} & \multirow[b]{2}{*}{$\begin{array}{c}\text { No. of oocytes } \\
\text { that reached } \\
\text { M-II }(\%)^{\mathrm{a}}\end{array}$} & \multicolumn{3}{|c|}{ Number of oocytes } & \multirow[b]{2}{*}{$\begin{array}{c}\text { Mean no. of } \\
\text { spermatozoa per } \\
\text { penetrated oocyte }\end{array}$} \\
\hline & & & & $\begin{array}{c}\text { Penetrated } \\
(\%)^{\mathrm{b}}\end{array}$ & $\begin{array}{c}\text { Polyspermic } \\
(\%)^{c}\end{array}$ & $\begin{array}{c}\text { With MPN } \\
(\%)^{c}\end{array}$ & \\
\hline DOs & $\begin{array}{c}0 \mu \mathrm{m} \\
\mathrm{AA}-2 \mathrm{G}\end{array}$ & 117 & $\begin{array}{c}72 \\
(62.3 \pm 4.6)^{\mathrm{de}}\end{array}$ & $\begin{array}{c}62 \\
(86.0 \pm 1.0)\end{array}$ & $\begin{array}{c}44 \\
(70.9 \pm 3.9)\end{array}$ & $\begin{array}{c}12 \\
(20.2 \pm 3.5)^{\mathrm{d}}\end{array}$ & $2.4 \pm 0.3$ \\
\hline DOs & $\begin{array}{l}100 \mu \mathrm{m} \\
\mathrm{AA}-2 \mathrm{G}\end{array}$ & 102 & $\begin{array}{c}55 \\
(54.4 \pm 5.3)^{\mathrm{de}}\end{array}$ & $\begin{array}{c}47 \\
(85.7 \pm 2.2)\end{array}$ & $\begin{array}{c}32 \\
(68.2 \pm 4.7)\end{array}$ & $\begin{array}{c}14 \\
(29.8 \pm 0.5)^{\mathrm{de}}\end{array}$ & $2.1 \pm 0.1$ \\
\hline DOs & $\begin{array}{l}250 \mu \mathrm{m} \\
\text { AA-2G }\end{array}$ & 110 & $\begin{array}{c}70 \\
(64.0 \pm 4.1)^{\mathrm{d}}\end{array}$ & $\begin{array}{c}60 \\
(85.5 \pm 2.2)\end{array}$ & $\begin{array}{c}41 \\
(68.6 \pm 3.3)\end{array}$ & $\begin{array}{c}26 \\
(43.4 \pm 2.2)^{\mathrm{f}}\end{array}$ & $2.3 \pm 0.4$ \\
\hline DOs & $\begin{array}{l}500 \mu \mathrm{m} \\
\text { AA-2G }\end{array}$ & 114 & $\begin{array}{c}56 \\
(49.1 \pm 4.1)^{\mathrm{ef}}\end{array}$ & $\begin{array}{c}44 \\
(77.1 \pm 5.8)\end{array}$ & $\begin{array}{c}29 \\
(68.3 \pm 5.2)\end{array}$ & $\begin{array}{c}16 \\
(38.1 \pm 6.2)^{\text {efg }}\end{array}$ & $2.2 \pm 0.1$ \\
\hline DOs & $\begin{array}{l}750 \mu \mathrm{m} \\
\text { AA-2G }\end{array}$ & 124 & $\begin{array}{c}45 \\
(36.6 \pm 2.9)^{\mathrm{f}}\end{array}$ & $\begin{array}{c}36 \\
(80.8 \pm 5.3)\end{array}$ & $\begin{array}{c}22 \\
(61.3 \pm 3.2)\end{array}$ & $(41.2 \pm 5.8)^{\mathrm{ef}}$ & $2.1 \pm 0.1$ \\
\hline DOs & $\begin{array}{c}250 \mu \mathrm{m} \\
\text { AsA }\end{array}$ & 103 & $\begin{array}{c}55 \\
(53.4 \pm 0.4)^{\mathrm{de}}\end{array}$ & $\begin{array}{c}43 \\
(78.3 \pm 2.5)\end{array}$ & $\begin{array}{c}27 \\
(62.1 \pm 8.7)\end{array}$ & $\begin{array}{c}12 \\
(27.7 \pm 2.8)^{\mathrm{dg}}\end{array}$ & $2.0 \pm 0.5$ \\
\hline COCs & $\begin{array}{c}0 \mu \mathrm{m} \\
\mathrm{AA}-2 \mathrm{G}\end{array}$ & 120 & $\begin{array}{c}110 \\
(91.8 \pm 2.9)^{\mathrm{g}}\end{array}$ & $\begin{array}{c}94 \\
(85.2 \pm 2.8)\end{array}$ & $\begin{array}{c}61 \\
(64.4 \pm 4.4)\end{array}$ & $\begin{array}{c}62 \\
(66.3 \pm 1.6)^{\mathrm{h}}\end{array}$ & $2.1 \pm 0.2$ \\
\hline
\end{tabular}

MPN=male pronucleus.

a Percentages within the number of oocytes examined (mean \pm SEM).

bercentages within the number of oocytes that reached M-II (mean \pm SEM).

${ }^{c}$ Percentages within the number of oocytes penetrated (mean $\left.\pm S E M\right)$.

d-h Values with different superscripts in the same column are significantly different $(P<0.05)$.

cytoplasmic maturation of porcine DOs.

The absence or presence of AA-2G during IVM culture in DOs caused no difference in the cleavage rate at $48 \mathrm{~h}$ after in vitro insemination $(57.6 \pm 4.6 \%$ or $60.8 \pm 1.7 \%$, respectively), but these proportions were lower than that of COCs $(73.3 \pm 1.4 \%)(P<0.05)$ (Fig. 1). In DOs matured without AA-2G, no embryo developed to the blastocyst stage following IVF, whereas, in DOs matured with AA-2G, $3.2 \pm$ $1.3 \%$ of IVM-IVF embryos developed to the 


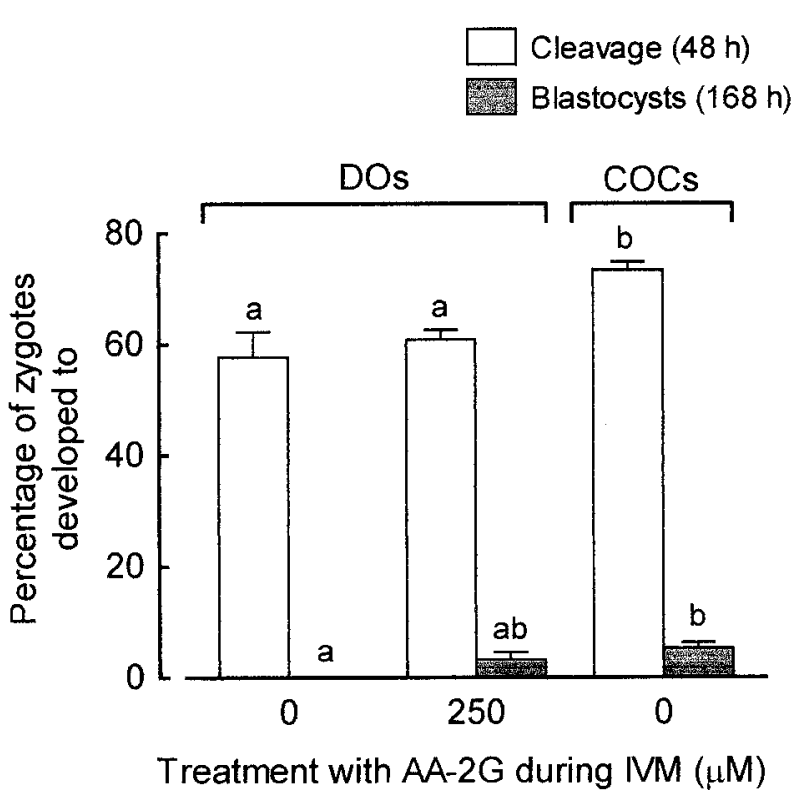

Fig. 1. Cleavage and blastocyst formation rates after IVF of porcine DOs and COCs matured with or without AA-2G. The findings are expressed as mean \pm SEM. Total number of oocytes examined was about 150 for each group. Within the same category, values with different superscripts are significantly different $(P<0.05)$.

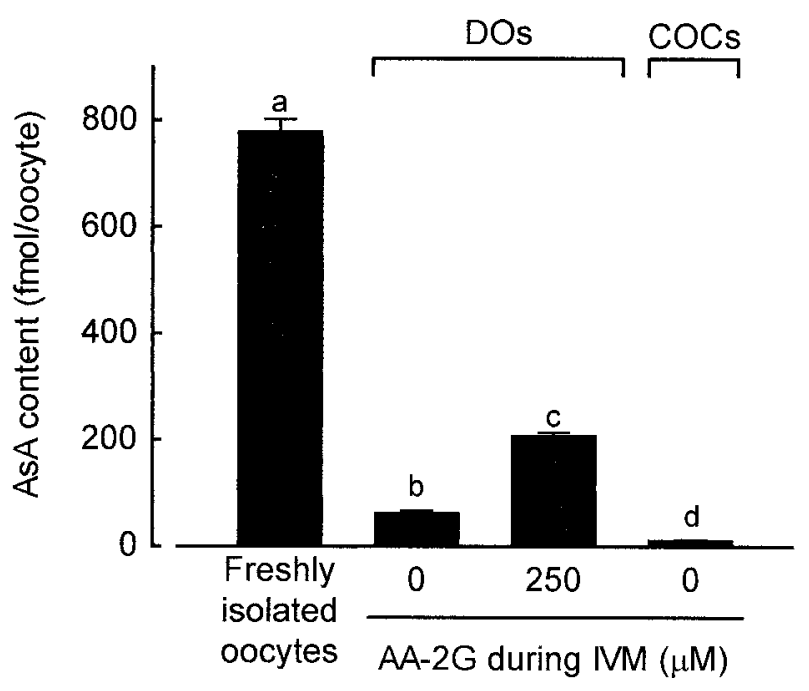

Fig. 2. Intracellular ascorbic acid (AsA) levels of porcine DOs and COCs matured with or without AA-2G. The values are expressed as mean \pm SEM. Values with different superscripts are significantly different $(P<0.05)$.

blastocyst stage. This rate almost approached that of COCs $(5.3 \pm 1.0 \%)$. Blastocysts derived from DOs matured with $250 \mu \mathrm{M}$ AA-2G and COCs contained a nucleus number of $34.5 \pm 3.8$ and $57.4 \pm 3.0$, respectively, when fixed and stained with $10 \mu \mathrm{g} / \mathrm{ml}$ bis benzimide Hoechst 33342 .

Effects of treatment with AA-2G on AsA, GSH contents, and DNA damage in DOs

As shown in Fig. 2, the concentration of intracellular AsA in oocytes freshly isolated from their follicles, referred to as "freshly isolated oocytes", was $779.2 \pm 22.8 \mathrm{fmol} /$ oocyte, but this value was significantly depleted during IVM culture $(P<0.05)$. In the absence of AA-2G, AsA contents of DOs and COCs were remarkably reduced to $62.6 \pm 5.1 \mathrm{fmol} /$ oocyte and $10.8 \pm 2.2$ fmol/oocyte, respectively. However, the level of intracellular AsA in DOs treated with AA-2G was elevated to $207.0 \pm 6.2 \mathrm{fmol} /$ oocyte. This value was significantly higher than those in oocytes treated without AA-2G $(P<0.05)$. In contrast, the treatment with $250 \mu \mathrm{M}$ AsA did not increase the level of intracellular AsA in DOs (77.0 $\pm 4.5 \mathrm{fmol} /$ oocyte) after IVM culture.

The intracellular GSH concentration in freshly isolated oocytes was $6.4 \pm 0.3 \mathrm{pmol} /$ oocyte, and the value in DOs treated without AA-2G was also decreased to $3.1 \pm 0.2 \mathrm{pmol} /$ oocyte during IVM culture $(P<0.05)$ (Fig. 3A). Treatment with AA-2G could alleviate the decrease of GSH content in DOs, showing a higher level of intracellular GSH (4.4 \pm $0.2 \mathrm{pmol} /$ oocyte) $(P<0.05)$. In contrast, GSH content in COCs was significantly increased to $7.3 \pm$ $0.2 \mathrm{pmol} /$ oocyte with the advance of oocyte maturation $(P<0.05)$. As shown in Fig. 3B, the length of DNA migration in DOs was significantly increased to $138.7 \pm 8.8 \mu \mathrm{m}$ compared to that of freshly isolated oocytes $(72.3 \pm 3.0 \mu \mathrm{m})(P<0.05)$. However, the addition of AA-2G to maturation medium protected DOs from DNA damage caused by oxidative stress, and the length of DNA migration in these oocytes $(93.6 \pm 4.2 \mu \mathrm{m})$ was almost the same as that in COCs $(81.0 \pm 3.9 \mu \mathrm{m})$ (Fig. 4).

\section{Discussion}

Both the maturation rate and the proportion of MPN formation in DOs were significantly lower than those in COCs (Tables 1 and 2). Yamauchi and Nagai [26] also reported these phenomena in 

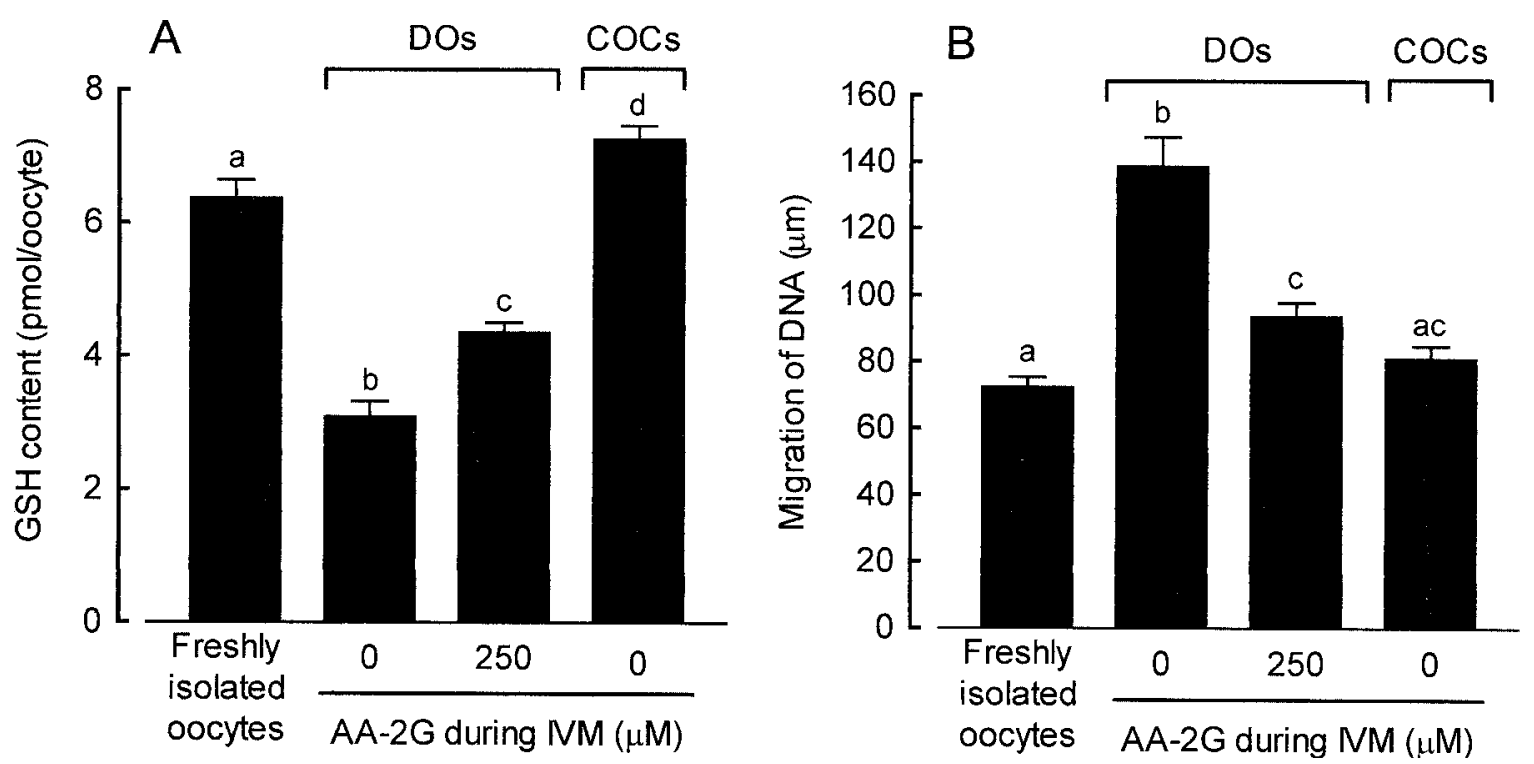

Fig. 3. Effects of treatment with or without AA-2G during IVM on the concentration of intracellular glutathione (GSH) (A) and the length of DNA migration (B) in porcine DOs and COCs. The values are expressed as mean \pm SEM. Values with different superscripts are significantly different $(P<0.05)$.
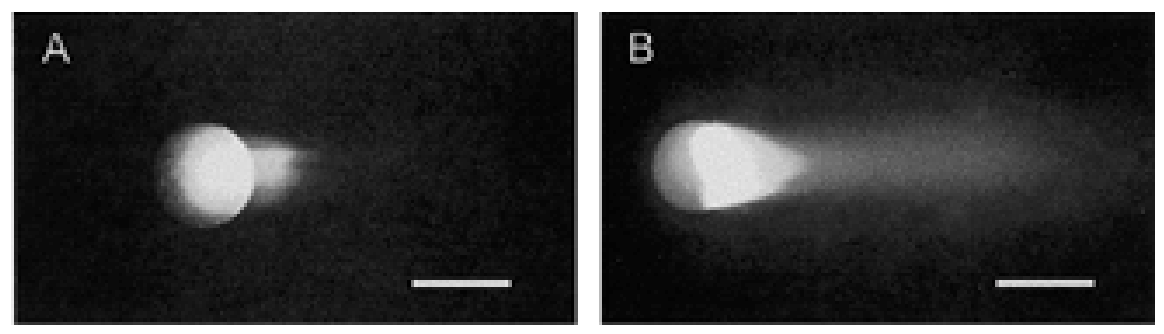

Fig. 4. Representative fluorescence photomicrograph of typical DNA migration patterns in porcine DOs treated with (A) or without (B) $250 \mu \mathrm{M}$ AA-2G for $44 \mathrm{~h}$. A) The DNA damage caused by oxidative stress was blocked by treatment with AA-2G. B) The increased length of DNA migration is demonstrated in the oocytes damaged by oxidative stress. Scale bars represent $100 \mu \mathrm{m}$.

porcine DOs. From these findings, it seems that cumulus cells during IVM culture of porcine oocytes must be associated with modulating oocyte maturation and supporting the ability to induce decondensation of the penetrated sperm nucleus. Although the importance of cumulus cells around the oocytes in promoting MPN formation after sperm penetration has been indicated for pigs [27] and cattle [8], the mechanism by which cumulus cells regulate MPN formation has not been sufficiently investigated yet. The presence of cumulus cells during IVM culture influenced RNA and protein syntheses in bovine oocytes [9, 28-30], and a number of metabolic products such as choline, uridine and inositol can enter the oocytes via cumulus cells, probably by direct intercellular transfer through the gap junctional communication in ovine oocytes [1]. These intercellular events between cumulus cells and oocytes via gap junctions appear to be involved in the developmental ability of the oocytes to form MPN after sperm penetration, but the factor(s) relating to cytoplasmic maturation remain to be detected.

When the gap junctional coupling between these cells during IVM was reduced by treatment with heptanol, a seven-carbon alcohol, GSH content of oocytes was decreased and the transformation of penetrated sperm nucleus into MPN was inhibited, 
suggesting that intracellular GSH of oocytes is a candidate for a factor which regulates MPN formation [31], as reported by Yoshida et al. [32] and Yoshida [33]. De Matos et al. [34] reported that cumulus cells play an important role in the GSH synthesis enhanced by the addition of cysteine and cysteamine during bovine oocyte maturation in vitro. The intracellular GSH of porcine oocytes may be a valuable marker for assessing the degree of cytoplasmic maturation and/or subsequent developmental potential of IVM-IVF embryos to the blastocyst stage [23]. In the present study, compared to freshly isolated oocytes, GSH content of DOs treated without AA-2G was significantly decreased in contrast to the finding that the GSH content of COCs increased with the advance of nuclear maturation (Fig. 3A). Furthermore, a significant increase in the length of DNA migration was found in DOs with a concomitant reduction in the levels of GSH content (Fig. 3B), as reported previously [12]. Intracellular GSH participates in not only the transformation of the penetrated sperm head into MPN in oocytes [35, 36], but also the protection of somatic cells against oxidative stress [13]. However, the functional role of antioxidants in supporting cytoplasmic maturation is still unknown.

It is undeniable that in vitro culture is carried out at higher concentrations of $\mathrm{O}_{2}$ than the in vivo environment, resulting in the increased production of reactive oxygen species [37]. Superoxide anion radicals produced by oxygen are detrimental to embryo development in mice $[38,39]$ and cattle [40, 41]. The oxidative stress during IVM culture provoked porcine oocytes into undergoing apoptotic cell death, judging from the findings of DNA cleavage by TUNEL analysis, the increased length of DNA migration by the comet assay, and the activation of caspase- 3 which was prominently detected in degenerated oocytes after treatment with hypoxanthine and xanthine oxidase [12]. Also cumulus cells played a critical role in protecting oocytes against oxidative stress-induced apoptosis through the enhancement of GSH content in oocytes [12], implying that DOs are highly susceptible to oxidative stress in comparison to COCs. Therefore, with regard to the protection of DOs against oxidative damage, it is very important to evaluate the concentration of AsA as one of the redox regulators $[14,15]$. The intracellular levels of AsA in DOs as well as COCs were reduced to a remarkably low level during IVM culture, although it remains to be resolved whether the difference between these two values represents a physiological difference. However, AsA in the medium is easily oxidized by oxygen under the culture conditions, indicating that it is difficult to maintain intracellular As A level by its supplementation at the beginning of culture [19, 20]. In fact, the present study found that treatment of DOs with $250 \mu \mathrm{M}$ AsA during IVM culture did not increase the proportion of MPN formation (Table 2) and the level of intracellular AsA, suggesting that the single addition of AsA to IVM medium was ineffective in achieving cytoplasmic maturation. In contrast, AA-2G functioned throughout the maturation culture period supplying AsA continuously. The addition of 250 $\mu \mathrm{M}$ AA-2G to maturation medium in DOs restored the concentration of intracellular AsA significantly (Fig. 2), resulting in the preclusion of length increase of DNA migration which is indicative of oxidative damage (Fig. 3B). These findings imply that AA-2G in maturation medium could potentiate the cellular protection of porcine DOs against oxidative damage as a powerful radical scavenger, providing a source of AsA which was accumulated within the ooplasm. However, treatment with higher concentrations of AA-2G (500 $\mu \mathrm{M}$ or 750 $\mu \mathrm{M})$ inhibited the induction of oocyte maturation in DOs (Tables 1 and 2), indicating that the incorporation of intracellular AsA beyond an optimum concentration range may have deleterious effects on maturation events. It is reported that AsA uptake in rat granulosa cells is energy- and $\mathrm{Na}^{+}$-dependent [42], and that AsA transporters, SVCT1 and SVCT2, have been recently cloned in the rat [43]. However, the existence of AsA transporters in porcine oocytes remains unclear.

In comparison to DOs matured without $A A-2 G$, a significantly high value of GSH content was detected in DOs matured with AA-2G (Fig. 3A), indicating that AsA derived from AA-2G plays an important role in maintaining the redox state of oocytes and protecting cells against the harmful effects of oxidative injuries, instead of the reducing process by intracellular GSH. As a consequence of the radical-scavenging activity of AsA, the ability of DOs treated with $250 \mu \mathrm{M}$ AA-2G during IVM culture to form MPN was effectively enhanced, compared with DOs matured in medium without 
AA-2G (Table 2), but the proportion of MPN formed in DOs matured with AA-2G was significantly lower than that of COCs, suggesting that treatment with AA-2G alone during IVM culture cannot improve the potential of DOs to form MPN to the same level as that of COCs. Nevertheless, the addition of AA-2G to maturation medium in DOs enabled IVM-IVF-derived zygotes to develop to the blastocyst stage (Fig. 1). To our knowledge, the present study is the first report to demonstrate that antioxidants during IVM culture of porcine DOs contributed to the enhancement of the subsequent developmental potential. From these findings, it is clear that the protection of oocytes against oxidative damage during IVM is important for supporting the cytoplasmic maturation responsible for the subsequent developmental competence post-fertilization. However, there was a significant difference in the quality of embryos, judging from the finding that the blastocysts derived from DOs matured with 250 $\mu \mathrm{M}$ AA-2G and COCs contained an average of 34.5 and 57.4 nuclei, respectively. Further studies are required to investigate whether additional treatments such as cysteamine, which lead to increases in the levels of GSH content in porcine DOs [26], is necessary for enhancing cytoplasmic maturation of porcine DOs by associating with the antioxidative activity of AA-2G.

In summary, the present study indicates that during IVM culture treatment with AA-2G, a stable form of AsA derivative, efficiently blocks DNA damage caused by oxidative stress, resulting in enhancement of the ability to develop to the blastocyst stage after in vitro insemination in porcine DOs. Therefore, it can be concluded that the protection of oocytes against oxidative damage during IVM culture substantially supports the cytoplasmic maturation responsible for the subsequent developmental competence postfertilization.

\section{Acknowledgments}

This research was supported by grants for scientific research from the Ito Memorial Foundation (to H.T.) of Japan, and from the Ministry of Education, Science Sports and Culture (no. 11760196 to H.T.) of Japan. We are grateful to the staff of the Meat Inspection Office of the city of Fukuyama, Japan, for supplying the porcine ovaries.

\section{References}

1. Moor RM, Smith MW, Dawson MC. Measurement of intracellular coupling between oocytes and cumulus cells using intracellular markers. Exp Cell Res 1980; 126: 15-29.

2. Larsen WJ, Wert SE. Role of cell junctions in gametogenesis and in early embryonic development. Tissue E Cell 1988; 20: 809-848.

3. Eppig JJ. The relationship between cumulus celloocyte coupling, oocyte meiotic maturation and cumulus expansion. Dev Biol 1982; 89: 268-272.

4. Buccione R, Schroeder AC, Eppig JJ. Interactions between somatic cells and germ cells throughout mammalian oogenesis. Biol Reprod 1990; 43: 543-547.

5. Binor $\mathbf{Z}$, Wolf DP. In vitro maturation and penetration of mouse primary oocytes after removal of zona pellucida. J Reprod Fertil 1979; 56: 309-314.

6. Magnusson C. Role of cumulus cells for rat oocyte maturation and metabolism. Gamete Res 1980; 3: 133-140.

7. Staigmiller RC, Moor RM. Effect of follicle cells on the maturation and developmental competence of ovine oocytes matured outside the follicle. Gamete
Res 1984; 9: 221-229.

8. Chian RC, Niwa K, Sirard MA. Effect of cumulus cells on the male pronuclear formation and subsequent early development of bovine oocytes in vitro. Theriogenology 1994; 41: 1499-1508.

9. Tatemoto $\mathbf{H}$, Horiuchi $\mathbf{T}$, Terada $\mathbf{T}$. Effects of cycloheximide on chromatin condensations and germinal vesicle breakdown (GVBD) of cumulusenclosed and denuded oocytes in cattle. Theriogenology 1994; 42: 1141-1148.

10. Kim SK, Minami N, Yamada M, Utsumi K. Functional role of cumulus cells during maturation in development of in vitro matured and fertilized bovine oocyte. Theriogenology 1996; 45: 278.

11. Geshi M, Takenouchi N, Yamauchi N, Nagai T. Effects of sodium pyruvate in nonserum maturation medium on maturation, fertilization, and subsequent development of bovine oocytes with or without cumulus cells. Biol Reprod 2000; 63: 17301734.

12. Tatemoto H, Sakurai N, Muto N. Protection of porcine oocytes against apoptotic cell death caused 
by oxidative stress during in vitro maturation: role of cumulus cells. Biol Reprod 2000; 63: 805-810.

13. Meister A. Selective modification of glutathione metabolism. Science 1983; 220: 472-477.

14. Buettner GR. The pecking order of free radicals and antioxidants: lipid peroxidation, $\alpha$-tocopherol, and ascorbate. Arch Biochem Biophys 1993; 300: 535-543.

15. Rose RC, Bode AM. Biology of free radical scavengers: an evaluation of ascorbate. FASEB J 1993; 7: 1135-1142.

16. Guarnaccia MM, Takami M, Jones EE, Preston SL, Behrman HR. Luteinizing hormone depletes ascorbic acid in preovulatory follicles. Fertil Steril 2000; 74: 959-963.

17. Tilly JL, Tilly KI. Inhibitors of oxidative stress mimic the ability of follicle-stimulating hormone to suppress apoptosis in cultured rat ovarian follicles. Endocrinology 1995; 136: 242-252.

18. Eppig JJ, Hosoe M, O'Brien MJ, Pendola FM, Requena A, Watanabe S. Conditions that affect acquisition of developmental competence by mouse oocytes in vitro: FSH, insulin, glucose and ascorbic acid. Mol Cell Endocrinol 2000; 163: 109-116.

19. Tolbert BM, Downing M, Carlson RW, Knight MK, Baker EM. Chemistry and metabolism of ascorbic acid and ascorbate sulfate. Ann NY Acad Sci 1975; 258: 48-69.

20. Yamamoto I, Muto N, Murakami K, Suga S, Yamaguchi H. L-Ascorbic acid $\alpha$-glucoside formed by regioselective transglucosylation with rat intestinal and rice seed $\alpha$-glucosidases: its improve stability and structure determination. Chem Pharm Bull 1990; 38: 3020-3023.

21. Muto N, Nakamura T, Yamamoto I. Enzymatic formation of a nonreducing L-ascorbic acid $\alpha$ glucoside: purifiication and properties of $\alpha$ glucosidase catalyzing site-specific transglucosylation from rat small intestine. J Biochem 1990; 107: 222-227.

22. Petters RM, Wells KD. Culture of pig embryos. J Reprod Fertil 1993; 48 (Suppl): 61-73.

23. Abeydeera LR, Wang WH, Contley TC, Rieke A, Day BN. Coculture with follicular shell pieces can enhance the developmental competence of pig oocytes after in vitro fertilization: relevance to intracellular glutathione. Biol Reprod 1998; 58: 213218.

24. Murakami K, Muto N, Fukazawa K, Yamamoto I. Comparison of ascorbic acid and ascorbic acid 2-O$\alpha$-glucoside on the cytotoxicity and bioavailability to low density cultures of fibroblasts. Biochem Pharmacol 1992; 44: 2191-2197.

25. Singh NP, McCoy MT, Tice RR, Schneider EL. A simple technique for quantitation of low level of DNA damage in individual cells. Exp Cell Res 1988; 175: 184-191.

26. Yamauchi N, Nagai T. Male pronuclear formation in denuded porcine oocytes after in vitro maturation in the presence of cysteamine. Biol Reprod 1999; 61: 828-833.

27. Wang WH, Abeydeera LR, Okuda K, Niwa K. Penetration of porcine oocytes during maturation in vitro by cryopreserved, ejaculated spermatozoa. Biol Reprod 1994; 50: 510-515.

28. Farin $\mathrm{CE}$, Yang $\mathrm{L}$. Inhibition of germinal vesicle breakdown in bovine oocytes by 5,6 -dichloro-1- $\beta$-Dribofuranosylbenzimidazole (DRB). Mol Reprod Dev 1994; 37: 284-292.

29. Chian RC, Sirard MA. Effects of cumulus cells and follicle-stimulating hormone during in vitro maturation on parthenogenetic activation of bovine oocytes. Mol Reprod Dev 1995; 42: 425-431.

30. Tatemoto $\mathbf{H}$, Terada $\mathbf{T}$. Time-dependent effects of cycloheximide and $\alpha$-amanitin on the meiotic resumption and progression in bovine follicular oocytes. Theriogenology 1995; 43: 1107-1113.

31. Mori T, Amano T, Shimizu H. Roles of gap junctional communication of cumulus cells in cytoplasmic maturation of porcine oocytes cultured in vitro. Biol Reprod 2000; 62: 913-919.

32. Yoshida M, Ishigaki K, Pursel VG. Effect of maturation media on male pronucleus formation in pig oocytes matured in vitro. Mol Reprod Dev 1992; 31: 68-71.

33. Yoshida M. Role of glutathione in the maturation and fertilization of pig oocytes in vitro. Mol Reprod Dev 1993; 35: 76-81.

34. de Matos DG, Furnus CC, Moses DF. Glutathione synthesis during in vitro maturation of bovine oocytes: role of cumulus cells. Biol Reprod 1997; 57: 1420-1425.

35. Calvin HI, Grosshans K, Blake EJ. Estimation and manipulation of glutathione levels in prepubertal mouse ovaries and ova: relevance to sperm nucleus transformation in the fertilized egg. Gamete Res 1986; 14: 265-275.

36. Perreault SD, Barbee RR, Slott VI. Importance of glutathione in the acquisition and maintenance of sperm nuclear decondensing activity in maturing hamster oocytes. Dev Biol 1988; 125: 181-186.

37. Luvoni GC, Keskintepe L, Breackett BG. Improvement in bovine embryo production in vitro by glutathione-containing culture media. Mol Reprod Dev 1996; 43: 437-443.

38. Umaoka Y, Noda Y, Narimoto K, Mori T. Effects of oxygen toxicity on early development of mouse embryos. Mol Reprod Dev 1992; 31: 28-33.

39. Gardiner CS, Reed DJ. Status of glutathione during oxidant-induced oxidative stress in the preimplantation mouse embryo. Biol Reprod 1994; 51: 1307-1314.

40. Nagao Y, Saeki K, Hoshi M, Kainuma H. Effects of oxygen concentration and oviductal epithelial tissue on the development of in vitro matured and 
fertilized bovine oocytes cultured in protein-free medium. Theriogenology 1994; 41: 681-687.

41. Shamsuddin $\mathbf{M}$, Larsson B, Gustafsson $\mathbf{H}$, Rodriguez-Martinez $\mathbf{H}$. A serum-free, cell-free culture system for development of bovine one-cell embryos up to blastocyst stage with improved viability. Theriogenology 1994; 41: 1033-1043.

42. Behrman HR, Preston SL, Aten RF, Rinaudo P,
Zreik TG. Hormone induction of ascorbic acid transport in immature granulosa cells. Endocrinology 1996; 137: 4316-4321.

43. Tsukaguchi H, Tokui T, Mackenzie B, Berger UV, Chen XZ, Wang Y, Brubaker RF, Hediger MA. A family of mammalian $\mathrm{Na}^{+}$-dependent L-ascorbic acid transporters. Nature 1999; 399: 70-75. 